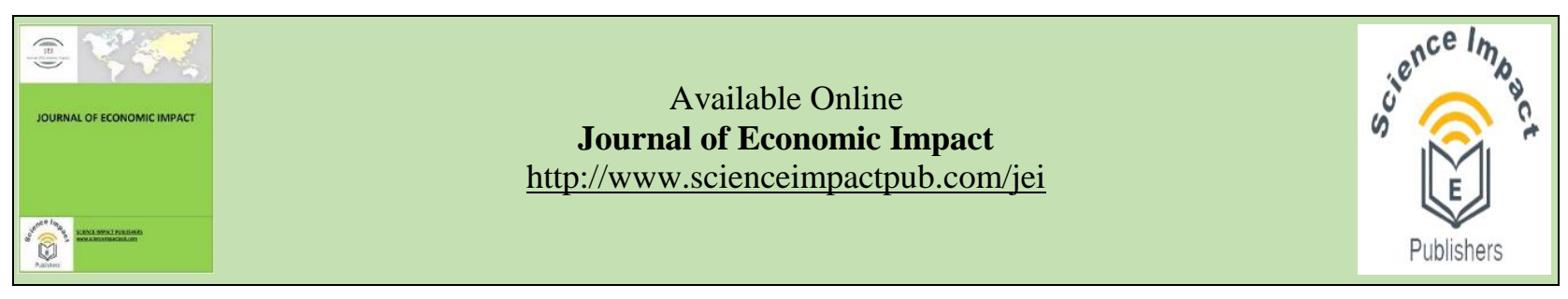

\title{
TECHNICAL EFFICIENCY AND ITS DETERMINANTS IN WHEAT PRODUCTION: EVIDENCE FROM PUNJAB, PAKISTAN
}

\author{
Maryam Nawaz ${ }^{\mathrm{a}}$, Shoaib Akhtar ${ }^{\mathrm{b}, *}$, Adnan Nazir $^{\mathrm{c}}$, Muhammad Faisal ${ }^{\mathrm{d}}$ \\ a School of Economics, Bahauddin Zakariya University, Multan, Punjab, Pakistan \\ b Department of Economics, University of the Punjab, Lahore 54590, Punjab Province, Pakistan \\ ${ }^{\mathrm{c}}$ Department of Agricultural Economics, Sindh Agriculture University, Tando Jam, Pakistan \\ ${ }^{\mathrm{d}}$ College of Economics and Management, Huazhong Agricultural University, Wuhan 430070, Hubei Province, P.R. China
}

\section{HIGHLIGHTS}

- According to the results of the study the estimated efficiencies results show that the mean technical efficiency of the wheat crop is about $70 \%$, the mean allocative efficiency is $74 \%$, and the mean cost efficiency is $52 \%$.

- The findings of the research reveal that wheat farmers of Punjab can minimize the cultivating cost by $48 \%$ to give the given level of production by using the inputs in optimum proportion and by instructive the technical efficiency.

- The findings of the study also show that the current level of production of wheat can be enhanced to $9 \%$ with the same level input by increasing the technical efficiency of farmers of wheat.

- As a finding of this research, policymakers should focus on farmers' extension and training programs to minimize the technical inefficiency of wheat farms.

\begin{abstract}
The purpose of the current study was to assess the allocative, technical, and economic efficiency of wheat crop produced in Punjab. Primary data were collected through a well-structured questionnaire. The economic efficiencies were estimated by the DEA technique using the farm level data gathered from 240 wheat growers of the Rajanpur district of Punjab, Pakistan. According to the results of the study the estimated efficiencies results show that the mean technical efficiency of the wheat crop is about $70 \%$, the mean allocative efficiency is $74 \%$, and the mean cost efficiency is 52\%. The findings revealed that Pakistani wheat farms could minimize production costs by up to $30 \%$ to ensure the same level of production, using resources in optimal proportions and increasing technical efficiency. The findings also reveal that the current level of wheat production can be amplified by up to $30 \%$ by mollifying the technical efficiency of wheat crop.
\end{abstract}

Keywords: Technical efficiency, determinants, wheat production, DAE, Punjab.

Received: Sep 29, 2019; Accepted: Dec 30, 2019; Published: April 30, 2020.

* Correspondence: Department of Economics, University of the Punjab, Lahore 54590, Punjab Province, Pakistan

Email: shoaibakhtar1799@gmail.com

\section{Introduction}

The development of the agricultural sector depends on the efficient and effective use of resources to achieve higher levels of agricultural production. Agriculture also distributes raw materials for many industries. Many industries have direct and indirect links with the agricultural sector (Al-Feel and ALBashir, 2012). Agriculture share in GDP is $18.5 \%$, it employs $38.5 \%$ of the total labor force and intentionally adds to export earnings (GOP, 2019). Cereals, including wheat, rice, and corn are the staple foods for most of Pakistan's population. Food security is heavily dependent on a steady supply of grain. Residents of the country also consume other foods to satisfy their dietary needs, but cereal foods are based on their nutritional needs (Nawaz et al., 2015). Wheat cultivation is one of the main crops in Pakistan. Pakistan is self-sufficient in terms of growing wheat because the geographical location of Pakistan is best suited for growing wheat. The particularly fertile lands of Punjab are best suited for cultivation and development. Punjab and Sindh are two well-known provinces of Pakistan due to healthy wheat yields (Waqas et al., 2014; Sattar et al., 2015). In the context of constant population growth, there is an urgent need to improve wheat production, so many factors affecting wheat yields, such as farm size, seeds, 
verandas, farm size, land preparation, agricultural machinery and social environmental factors, namely infrastructure, markets, politics, state, and international trade. (Passel et al., 2006, Akhtar et al. 2015). Barkley et al. (2010) in its results, it was found that there are three ways to use different characteristics to increase the stability of crops: (1) traditional wheat breeding and advanced biotechnological breeding methods; (2) a mixture of varieties; and (3) a portfolio of varieties. Gorton and Davidova (2004) found that variables are two kinds, such as structural factors and capital human. Capitalhuman consists of informal and non-formal variables such as education, reading and writing skills, the experience of farming and training, and how old are the growers. Structural factors consist of income of the household, number of family members, debt access, landholding, sex structure of the labor force, farm and off-farm income, and variables of climate. Skilled farmers have many sources of earning and they are not entirely dependent on agriculture for livelihoods (Rahman, 2002).

This study contributes by estimating efficiency and by identifying its influencing economic and social factors. Efficiency analysis mainly focuses on creating the optimal level of production from a given level of combination of resources at the lowest cost (Russell and Young, 1983). Economic efficiency (EE) is the capacity of the growers who produces the lowest costs at each level. EE can be separated into the efficiency of allocative and efficiency of technical (Farrell, 1957). Allocative efficiency (AE) refers to the proper choice of input combination. If output resources are properly utilized according to their relative choices, the field is allocated efficiently. Technical efficiency (TE) refers to the right choice of production functions among all those aggressively used by farmers. A farmer is technically efficient if it harvests the highest achievable level of production from a constant amount of inputs. The stochastic production limit is an econometric technique that allows you to measure productivity in accordance with the ratio of the predicted (maximum) efficiency obtained by the production outlier function, taking into account the stochastic nature of the given input and output data. The purpose of this research was an attempt to assess the technical efficiency of the production of wheat and determine its main factors influencing it. Furthermore, this research attempted to find policy proposals that would help policymakers to enhance the production of wheat in southern Punjab, Pakistan

\section{Methodology}

Primary data is collected from wheat growers of district Rajanpur. For this purpose, 240 wheat farmers were randomly selected. The data were collected by personal interviews of respondents through the questionnaire. Wheat production and input are measured on a farm. Production is measured as wheat per hectare per farm. There are six inputs, including a hectare of arable land for wheat, for a working day, the amount of fertilizer in the field, the amount of fertilizer per farm, irrigation per acre in the field, the number of tractor hours per hour and the number of seeds in the field.

During the current study underhand technical efficiency, allocative efficiency and economic efficiency are estimated for sample wheat farmers in the Rajanpur district of Punjab using data envelopment analysis (DEA), an unconventional approach based on mathematical programming methods. The Data Envelopment Analysis (DEA) method was first presented by Charnes et al. (1978), which was based on the research work of Boles (1966), Farrell (1957), Afriat (1972) and Shephard (1970). Charnes et al. (1978) presented a data-oriented performance measurement, assuming constant scaling technology (CRS). The creation of CRS was softened by the Banker (1984), who proposed variable returns for a scaled DEA model. A detailed DEA technique is provided by Fried et al. (2008), Coelli et al. (2005), and Fare et al. (1994), which was considered when developing the Data Envelopment Analysis (DEA) model of this study. The Data Envelopment Analysis (DEA) approach was presented for a single result and several inputs, as in the current study. We used the return Data Envelopment Analysis DEA) method for weighting technology. Suppose that $n$ companies produce one product using inputs $\mathrm{K}$. To estimate the technical efficiency of a given firm $\mathrm{j}$ focused on input resources the following linear programming problem was solved. Input oriented variable return to scale DEA technique is applied for the estimation of technical efficiency as followed by (Coelli et al., 1998). It is specified as:

$$
\min _{\theta,\left\{\lambda_{i}\right\}_{i=1}^{n}} \theta
$$

Subjet to:

$$
\begin{aligned}
& \sum_{i=1}^{n} \lambda_{i}=1 \\
& \lambda_{i} \geq 0
\end{aligned}
$$$$
\sum_{i=1}^{n} y_{i} \Lambda_{i} \geq y_{j}
$$$$
\sum_{i=1}^{n} x_{k i} \lambda_{i} \leq \theta x_{k j}, \text { for } k=1,2, \ldots, K
$$

where ${ }^{\theta}$ is the input-oriented estimates of firm $\mathrm{j}$ 
technical efficiency, ${ }^{y i}$ is the production of $\mathrm{i}$ firm produced by, where $i=1,2, \ldots, j, \ldots, n$, and $n$ is the number of firms, ${ }^{x k i}$ is the $\mathrm{k}$ input quantity applied by $\mathrm{i}$ firm (for $\mathrm{i}=1,2, \ldots, \mathrm{j}, \ldots, \mathrm{n}$ ) for $\mathrm{k}=1,2, \ldots, \mathrm{K}$, where $\mathrm{K}$ is the number of inputs used by the firms, and ${ }^{[\lambda i}$ ${ }^{\prime}{ }^{i n}=1$ are the weights to be estimated. Note that there are $\mathrm{K}$ equations in Equation (3). The above model, given in Equations (1) - (4), is solved for $\mathrm{j}$ firms to get the optimum level of defined function, ${ }^{\theta^{*}}$, which is an estimate of the input-oriented technical efficiency of $j$ firm (TEj).

$$
T E_{j}=\theta^{*}
$$

To examine the input-oriented cost efficiency of $j$ firms, given linear programming problem is explained:

$$
\min _{\substack{x\}_{k j}^{K},\{\lambda\}^{n} \\ k=1}} \sum_{i=1}^{K} w \underset{k j}{x} x_{k j}
$$

subject to:

$$
\begin{aligned}
& \sum_{i=1}^{n} y_{i} \lambda_{i} \geq y_{j} \\
& \sum_{i=1}^{n} x_{k i} \lambda_{i} \leq x_{k j}, \text { for } k=1,2, \ldots, K \\
& \sum_{i=1}^{n} \lambda_{i}=1 \\
& \lambda_{i} \geq 0
\end{aligned}
$$

where ${ }^{w k j}$ is the input price $\mathrm{k}$ which is applied by $\mathrm{j}$ firm. In Equations (7) - (11) model is given, and it is calculated for $\mathrm{j}$ firms to get the optimal solution: $\left\{x^{*}\right\} K=$ and $\left\{\lambda_{i}^{*}\right\}_{i=1}^{n}$. Cost efficiency of $\mathrm{j}(\mathrm{EEj})$ firm is estimated:

$$
E E_{j}=\begin{aligned}
& \sum_{k=1}^{K} w_{k j} x_{k j}{ }^{*} \\
& \sum_{k j}^{k} w_{k j}
\end{aligned}
$$

Using Equations (6) and (12) we computed the allocative efficiency of firm $j\left(A E_{j}\right)$ is given below:

$$
A E_{j}=\frac{E E_{j}}{T E_{j}}
$$

following linear programming problem is solved:

$$
\max _{\varphi,\left\{\lambda_{i}\right\}_{i}^{n}=1} \varphi
$$

subject to:

$$
\begin{aligned}
& \sum_{i=1}^{n} \quad y_{i} \lambda_{i} \geq \varphi y_{j} \\
& \sum_{i=1}^{n} x_{k i} \lambda_{i} \leq x_{k j}, \text { for } k=1,2, \ldots, K \\
& \sum_{i=1}^{n} \lambda_{i}=1 \\
& \lambda_{i} \geq 0
\end{aligned}
$$

where $\varphi \geq 1$, and $(\varphi-1)$ is proportionally enhanced in the production that could be gained by firm $j$ same level of the input. The above model, given in Equations (14) - (18), is solved for firm $j$ to find the optimum value of the objective function, $\varphi^{*}$. To shows it in relative measure, the output-oriented technical efficiency of firm $j\left(T E O_{j}\right)$ is defined as:

$$
T E O=\frac{1}{\varphi^{*}}
$$

This technical efficiency estimates fulfil these bounds: $0<T E O_{j} \leq 1$, where the value of 1 indicates a fully efficient firm. Using DEAP 2.1 software to solve these problems, which was developed by Coelli (1996).

\section{Results and Discussion}

Technical, economic, and allocative efficiencies are assessed by the Data envelopment approach for each of Pakistan's 240 selected wheat farms. Table 1 provides descriptive statistics of performance indicators, including mean, standard deviation, and min and max values. The finding of the study shows that the mean effort-oriented measure of technical efficiency is 0.70 , which showed that on mean $30 \%$ of the effort to be minimized by enhancing the technical efficiency of the fields to achieve the monitored level of output of wheat. The mean result of effort-oriented allocative efficiency is 0.74 , which indicates that medium-sized wheat farms can minimize production costs by $26 \%$ by using resources in a proper way, even without increasing technical efficiency, given their respective values. 
Table 1: Summary of Efficiency Estimates Wheat Farmers in Punjab Pakistan

$\begin{array}{cccc}\text { Input-oriented } & \text { Input-oriented } & \text { Input-oriented } & \text { Output-oriented } \\ \text { Technical Efficiency } & \text { Allocative Efficiency } & \text { Economic Efficiency } & \text { Technical } \\ \text { Efficiency }\end{array}$

\begin{tabular}{ccccc}
\hline Mean & 0.70 & 0.74 & 0.52 & 0.91 \\
Std. dev. & 0.11 & 0.17 & 0.16 & 0.07 \\
Min & 0.44 & 0.31 & 0.23 & 0.77 \\
Max & 1.00 & 1.00 & 1.00 & 1.00 \\
\hline
\end{tabular}

Table 2: Estimates of Frequency Distribution (in \%) of Farms in Punjab Pakistan

\begin{tabular}{ccccc}
\hline & $\begin{array}{l}\text { Input-oriented } \\
\text { Technical efficiency } \\
\text { (\% Farms) }\end{array}$ & $\begin{array}{c}\text { Input-oriented } \\
\text { Allocative efficiency } \\
\text { (\% Farms) }\end{array}$ & $\begin{array}{c}\text { Input-oriented } \\
\text { Economic Efficiency } \\
\text { (\% Farms) }\end{array}$ & $\begin{array}{c}\text { Output-oriented } \\
\text { Technical Efficiency } \\
\text { (\%Farms) }\end{array}$ \\
\hline $0.20-0.30$ & 0 & 0 & 6.67 & 0 \\
$0.30-0.40$ & 0 & 2.5 & 18.33 & 0 \\
$0.40-0.50$ & 1.67 & 5.83 & 28.33 & 0 \\
$0.50-0.60$ & 15 & 19.17 & 20 & 0 \\
$0.60-0.70$ & 37.5 & 15 & 15 & 3.33 \\
$0.70-0.80$ & 32.5 & 20.83 & 5.83 & 40 \\
$0.80-0.90$ & 6.67 & 10.83 & 3.33 & 56.67 \\
$0.90-1.00$ & 6.67 & 25.83 & 2.5 & 100 \\
\hline Total & 100 & 100 & 100 & 0 \\
\hline
\end{tabular}

The findings indicate that, on the mean, farms have less technical efficiency $(0.70)$ rather than allocative efficiency (0.74). The mean cost-oriented economic efficiency is 0.52 , which means that farms of wheat can minimize production costs by up to $48 \%$ by using resources to produce the same level of production, taking into account their respective values in optimal proportions and reviving their technical features.
Table. 1 indicates that the average technical indicators oriented to production are 0.91 , which indicates that the detected level of mean wheat production is $91 \%$ of the possible products that can be produced at the same level of input. This means that by improving the technical efficiency of wheat fields, the current level of wheat production with the same input level can be increased to 9-9 percent. 


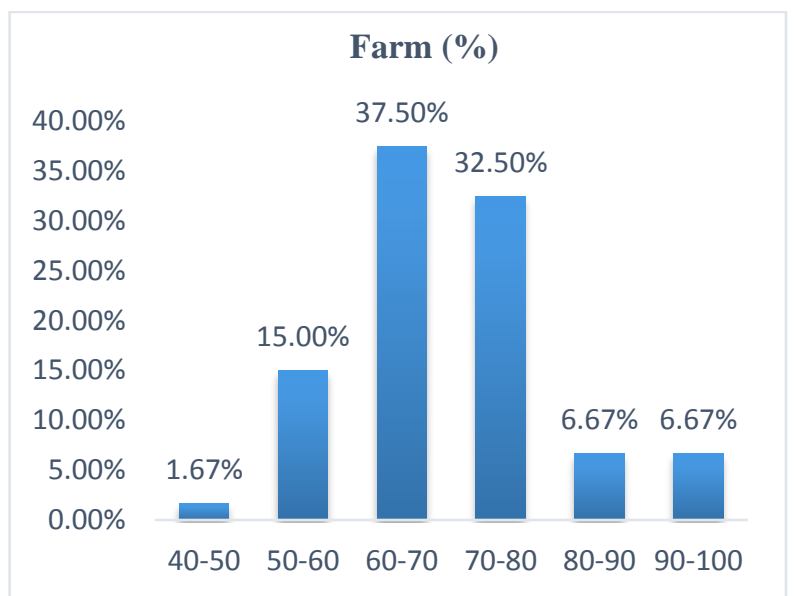

Input-oriented Technical Efficiency

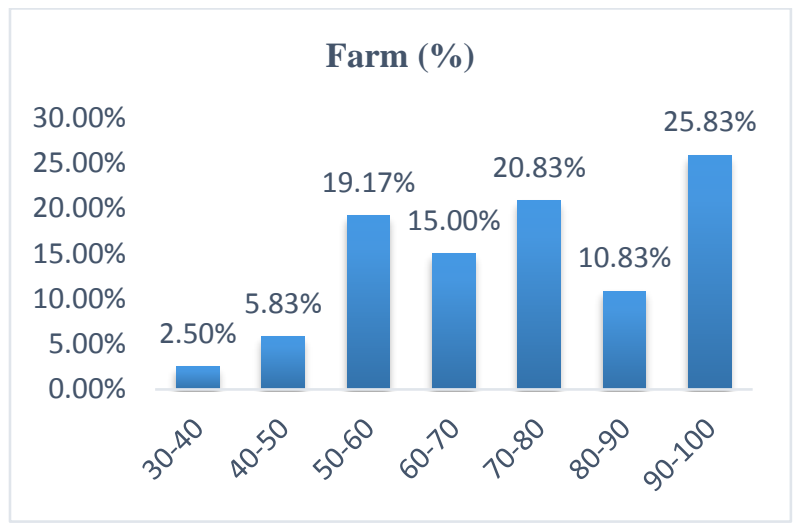

Input-oriented AE
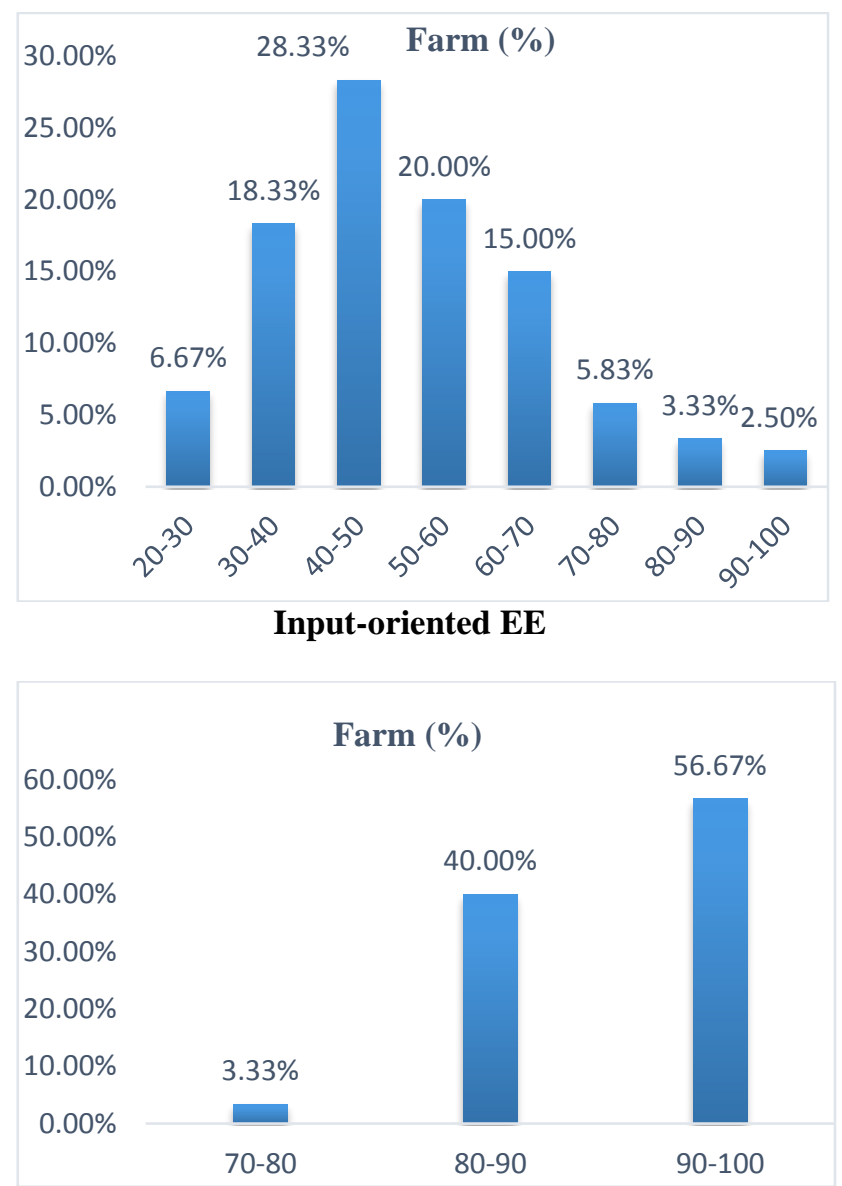

Output-Oriented TE

Figure 1: Efficiency Measures of Wheat Farms in Punjab Pakistan (Histogram)

Table 1 also shows the standard deviations of numerous performance indicators. 0.11 was the Std. dev in the input-oriented technical efficiency evaluates 0.17 in input-oriented allocative efficiency, and 0.16 in input-oriented economic efficiency. These findings show that the difference in farm allocative efficiency is smaller compared to other performance indicators. Table 2 shows the distribution of the relative frequency (in \%) of numerous indicators of wheat field productivity in Punjab. Histograms of these distributions are presented in Figure 1. The differences in farm allocative efficiency are smaller compared to other performance indicators because about 91.8 percent of wheat fields have a distribution efficiency in the range of 0.50-1.00. The findings of the study reveal that cost-oriented economic efficiency diverges from farm to farm, with many farms $(81.6 \%)$ having economic efficiencies in the range of $0.30-0.70$.

\section{Conclusions}

This article investigates the technical, allocative, and cost efficiencies of farmers of wheat in Punjab,
Pakistan. Primary data was collected from 240 wheat producers in Punjab, Pakistan. The findings of the research reveal that wheat farmers of Punjab can minimize the cultivating cost by $48 \%$ to give the given level of production by using the inputs in optimum proportion and by instructive the technical efficiency. The findings of the study also show that the current level of production of wheat can be enhanced to $9 \%$ with the same level input by increasing the technical efficiency of farmers of wheat. As a finding of this research, policymakers should focus on farmers' extension and training programs to minimize the technical inefficiency of wheat farms. Crop management techniques for all fields should be unwavering and provided to the farmers in a wellorganized way.

\section{References}

Al-Feel, M.A., AL-Basheer, A.A.R., 2012. Economic efficiency of wheat production in Gezira scheme, Sudan. Journal of the Saudi Society of Agricultural Sciences, 11(1), 1-5. http://doi.org/10.1016/j.jssas.2011.08.001 
Akhtar, S., Hussain, M., Hassan, S., Iqbal, N., 2015. Economics and dependence of wheat productivity on farm size in Southern Punjab. J. Environ. Agric. Sci. 2(4), 1-5.

Afriat, S.N., 1972. Efficiency estimation of production functions. International Economic Review, 13(3), 568-598.

Barkley, A., Peterson, H.H., Shroter, J., 2010. Wheat variety selection to maximize returns and minimize risk: An application of portfolio theory. J. Agric. App. Econ., 42(1), 39-55.

Boles, J.N., 1966. Efficiency squared--Efficient computation of efficiency indexes. In Proceedings of the Annual Meeting (Western Farm Economics Association) (Vol. 39, pp. 137-142). Western Agricultural Economics Association.

Charnes, A., Cooper, W.W., Rhodes, E., 1978. Measuring the efficiency of decision making units. European Journal of Operational Research, 2(6), 429-444.

Coelli, J., Rao, P., Christopher, J., Donnell, O., Battese, E., 2005. An introduction to efficiency and productivity analysis (2nd ed.). New York, USA: Springer Science and Business Media pp. 53-67

Coelli, T., 1996. A guide to DEAP version 2.1: a data envelopment analysis (computer) program. Centre for Efficiency and Productivity Analysis, University of New England, Australia, 96(08).

Coelli, T.J., Rao, D.P., O’Donnell, C.J. and Battese, G.E., 1998. An introduction to productivity and efficiency analysis. Springer Science: New York.

Fare, R., Färe, R., Fèare, R., Grosskopf, S. and Lovell, C.K., 1994. Production frontiers. Cambridge university press.

Farrell, M.J., 1957. The measurement of productive efficiency. J. Royal Stat. Soc., 120(3), 253-290.

Fried, H.O., Lovell, C.K., Schmidt, S.S. and Schmidt, S.S. eds., 2008. The measurement of productive efficiency and productivity growth. Oxford University Press.

GOP, 2018. Economic Survey of Pakistan. Finance Division 2018-2019, Economic Advisor's Wing, Islamabad, Pakistan.

Gorton, M., Davidova, S., 2004. Farm productivity and efficiency in the CEE applicant countries: A synthesis of results. Agric. Econ., 30, 1-16.

Nawaz, H., Hussain, N., Yasmeen, A., Arif, M., Hussain, M., Rehmani, M.I.A., Chattha, M.B. Ahmad, A., 2015. Soil applied zinc ensures high production and net returns of divergent wheat cultivars. Journal of Environmental and Agricultural Sciences, 2(1), 1-7.

Passel, S.V., Lauwers, L. and Van Huylenbroeck, G., 2006. Factors of Farm Performance: an Empirical Analysis of Structural and Managerial Characteristics. In Causes and Impacts of Agricultural Structures (pp. 3-22). Nova Science.

Rahman, K.M., 2002. Measuring efficiency of producing rice in Bangladesh: A stochastic frontier analysis. Department of Agriculture and Social Sciences, Justus - Liebig University, Giessen, Germany.

Russell, N.P., Young, T., 1983. Frontier production functions and the measurement of technical efficiency. Journal of Agricultural Economics 34, 139-150.

Sattar, A., Iqbal, M.M., Areeb, A., Ahmed, Z., Irfan, M., Shabbir, R.N., Aishia, G., Hussain, S., 2015. Genotypic variations in wheat for phenology and accumulative heat unit under different sowing times. J. Environ. Agric. Sci., 2(80, 1-8.

Shephard, R.W., 2015. Theory of cost and production functions. Princeton University Press.

Waqas, M., Faheem, M., Khan, A.S., Shehzad, M., Ansari, M.A.A, 2014. Estimation of heritability and genetic advance for some yield traits in eight F2 population of wheat (Triticum aestivum L.). Sci. Lett., 2(2), 43-47. 